\title{
The New Cognition of Supply Chain Integration: Management Interface Integration
}

\author{
Tao Wu, Shuojia Guo, and Rong-qiu Chen \\ Management school, Huazhong University of Science and Technology, \\ Wuhan, 430074,wut@wuhan.gov.cn
}

\begin{abstract}
As the basic concept of the management integration, the management interface can indicate the connection ways and mechanism of the node enterprises in the supply chain. According to the analysis on the principle of the management interface integration, three patterns of supply chain management integration is put forward here, which not only provides a new way to research on the supply chain integration, but also adds new connotation for the integrative philosophy in supply chain management.
\end{abstract}

\section{Preface}

Serving as the new mode of the operation of the modern enterprise, supply chain has drawn the wide attention in the circle of academy and enterprise home and aboard on the aspect of its operation, especially a large amount of research achievements have been done in the information integration, further the relevant software as ERP, SCM, CRM, APS and SRM has been introduced. Presently the integration research of these systems is being done with the combination of the operation practice of the supply chain in order to constitute the integration interface of the supply chain meaningfully, so the knitted enterprises can be connected and communicated effectively through the information interface to respond the market demand quickly.

However, as an integration system, supply chain relies on the supplying and demanding. Under the circumstances of the complete competition, the motive of this relation integration is that Nash Equilibrium solution of the non-corporation does not make the income of the knitted enterprises Pareto Efficiency, but through the corporation, the overall interests of the supply chain are increased to make the income of the knitted enterprises higher than Nash equilibrium. Therefore, the integration of this supplying and demanding relationship manifests in the integration

Please use the following format when citing this chapter:

Wu, T., Guo, S., Chen, R., 2006, in International Federation for Information Processing, Volume 205, Research and Practical Issues of Enterprise Information Systems, eds. Tjoa, A.M., Xu, L., Chaudhry, S., (Boston:Springer), pp.623-632. 
of logistics; integration of information and the management integration of supply chain. The broad sense of management makes many scholars combine management with logistics, management with information trend, so there exists a limitation to do the research on the integration of supply chain from one aspect.

The research on the integration of supply chain all covers the connotation of management, and the value chain after the integration mainly manifests in the form of entity value flow and virtual value flow. But the optimization of the supply chain value flow is realized through the management activities, which determine the direction of the entity value flow and virtual value flow in the supply chain, and there exists an independent management interface to the information system among the entity value activities, so the integration research on the supply chain management interface will add new connotation to the supply chain integration and the philosophical thoughts of supply chain management.

\section{Supply Chain and Supply Chain Management}

Supply chain is the new mode of the modern enterprise operation. First of all, the structure of supply chain should be defined clearly. Now many scholars home and aboard don't hold identical views on the connotation of supply chain. On the basis of analysis of supply chain, Mentzer and DeWitt [1] divided supply chain into three classes according to the complexity of supply chain: direct supply chain, extended supply chain and ultimate supply chain, which is demonstrated as Fig 1.

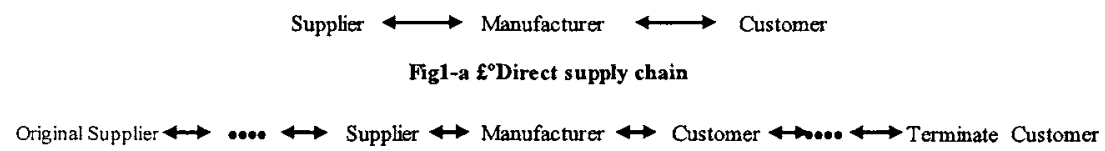

Fig1-b $E^{0}$ Extended supply chain

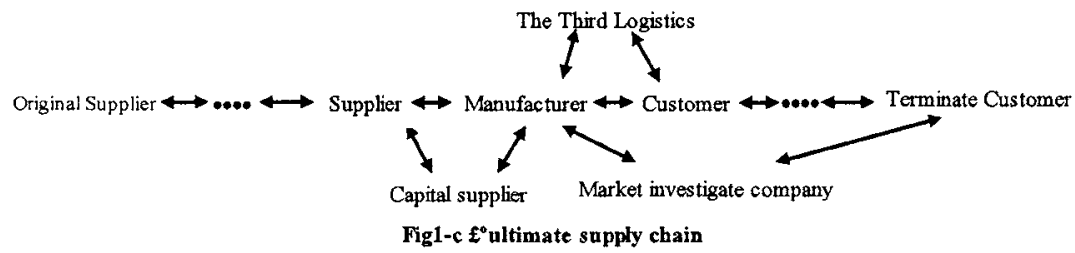

Fig. 1. Catalog of the Supply Chain Channels

Obviously this kind of division is based on the complexity degree of the relationship of supplying and demanding among the knotted enterprises. A brief description on the supply chain is given in Fig 1, which demonstrates that the direct supplying chain is ordinarily composed of one manufacturer, one suppler and one customer, and involves the stream of products, service, fund and information from the upper reaches to the lower reaches. The extended supply chain is described in Fig 
1-b. On the basis of the direct supply chain, the original supplier, the supplier of the upper reaches, is added, the terminate customer, the customer of the lower reaches, is added, the general supply chain description is given. The terminate supply chain includes all the organizations of the upper and lower reaches, such as the third logistics, the third fund provider and market investigation company, so that a complete supply chain description is given.

The supply chain, no mater which level it is in, exists in the reality before the conception of the supply chain was proposed. Because of the insufficient supply in the society, larger profit still can be made through the competition among the enterprises in the supply chain, so that the corporation among the enterprises of the upper and lower reaches is neglected.

As long as the rapid development of the productive forces and the enriching supply in the society, major markets have been turned into the buyer from the seller, so that the market competition becomes more fierce, in addition, the customer' expectations, the enterprises' risks, the cost pressure, the products' quality and reliability have been increased. Meanwhile, the opportunity window of the products is reduced, the maintaining time of the product's cycle and difference, and the introduction time of the new product is shortened, etc. The operation mode dominated by the competition among the enterprises not only hinders the development of the enterprise, but also effect the level of the whole supply chain's response to the customer's demanding. Therefore the management of the supply chain becomes the important topic to make the strategies in and out of the enterprises.

The management of the supply chain is a kind of management philosophy, which views the supply chain a whole with a systematical viewpoint; the respective functions are fulfilled not in accordance with the different enterprises or sections alone [2 - 4]. In other words, the supply chain management philosophy is the conception of the extending relationship, which makes most enterprises cooperatively to manage all the logistics from the supplier to the terminate customer [2]. Therefore the supply chain management, as the management philosophy, is to seek the synchronization and integration of unity of the operation and strategic ability in the enterprises and among the enterprises. (Ross 1998).

In the management and practice of the supply chain, the enterprises are to make their operation and the supply chain management's philosophy thoughts act in unison. The enterprises can mutually share the information, mutually share the risks and rewards, corporate for the same target, concern on the same customers' service, integrate the process, construct the partners and maintain the long term partner relationship, etc to fulfill successfully the supply chain management philosophy.

\section{The Proposal of the Supply Chain Management Interface}

The supply chain management philosophy is a whole-viewpoint-applied systematic thought in the supply chain management. The supply chain, an artificial system, is 
constituted through the integration. It is known that management is a way of integration, so the supply chain management is a kind of the integration of the supply chain. It is an important aspect of the integration of the supply chain that the supply chain is managed generally from the supplier to the supplier and from the customer to the customer. Furthermore, the management of the whole supply chain is based on the integration of the management, which can be regarded as the supply chain integration.

The relationship among the enterprises in the supply chain is a direct and indirect supply and demanding relationship, the enterprises connect with each other through the logistics, the flow of information and fund, so the direct demonstration of the supply chain integration is the integration of the logistics, information flow and fund flow. Through the integration of the logistics, information flow and fund flow, the operation of the supply chain is conformed. But the logistics, information flow and fund flow in the supply chain can not be dispatched from the content of the management, even can be dominated by the management, for example. Such management activities as the storage strategy, supplying strategy, manufacture strategy, sale strategy dominate the tread, amount and process of the materials. In addition, the entity and virtual the value flow in the supply chain can be bettered through the management of the supply chain.

The specific connection among the enterprises in the supply chain can be described by the interface among the enterprises in the supply chain. The direct and object interface among the enterprises in this supply chain mainly include the materials interface (embodied through the logistics), the information interface (embodied through the information flow) and fund interface (embodied through the fund flow). But in the supply chain, the logistics, information flow and fund flow are governed by the management. It is through the management activities that the value flow of the supply chain can be bettered and the right treads of materials, information and fund. Obviously these entities or virtual interfaces contain the content of the management, that is to say, there exists the management relationships among the enterprises in the supply chain---the management interface, and the supply chain management integration is mainly embodied in the management interface integration. Therefore the management interface integration is the important content of the supply chain management integration.

\section{The Principle of the Supply Chain Management Interface}

The supply chain management interface can be indicated by three categories, see Fig. 2. 


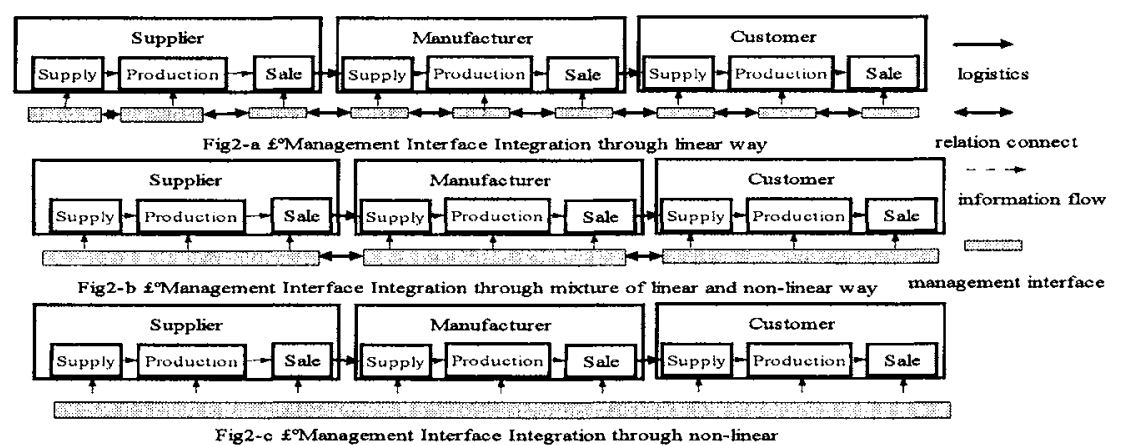

Fig. 2. The Three Categories of Management Interface Integration

Fig. 2-a indicates that the interior entities of the knotted enterprises in the supply chain are confirmed through the integration' linear connection (Here they are also called interfaces, but initial interfaces). When the information technology is not advanced, the management integration of the enterprise is ordinarily based on the initial management linear confirmation inside the enterprise, and then in this enterprise, the function can probably be doubled because of the management integration. The supply chain confirmation among the enterprises is based on the initial management interface linear confirmation. For example, the confirmation of the supplier and the producer is fulfilled through the interface confirmation (connection) between the sales department of the supplier and the supplying department of the producer, and it is similar that the confirmation of the producer and the customer is based on the linear confirmation process. Thus through the linear interface confirmation, the supply chain's function will be probably doubled. Its linear double relationship can be indicated by $E_{A}+E_{A}+E_{A}=k E_{A},(k>3)$, $E_{A}$ is a single function, which explains that the whole function $k E_{A}$ is the linear doubled after the three units with the function of $E_{A}$ are linear confirmed.

Fig. 2-b indicates that the connection among the value entities in the knotted enterprise in the supply chain is no longer through the linear joint connection, but through the non-linear confirmation of the management interface among the value entities, so that the enterprise management interfaces in formed ${ }^{[10]}$. The whole operation of the value entities in the enterprise is fulfilled through the enterprise's management interface, that is to say, through the management interface of the enterprise, to realize the connection of the arbitrary value entities in the enterprise's management interface, so that the synchronous operation and the function emerging of the supply chain in the enterprise come into being. The connection among the knotted enterprises in the supply chain (among the enterprises having direct supplying and demanding relationship) is also based on the enterprises' management interfaces. Through the interface confirmation between the two enterprises, the nonlinear confirmation can be realized among the enterprises. But the management connection among the enterprises having no direct supply and demanding relationship is realized through the linear way after its non-linear confirmation with 
the enterprises having direct supply and demanding relationship. For example, in Fig. 2, the management relationship between the supplier and the customer, through the non-linear confirmation of the supply and demanding interface between the producer and the supplier, and after the non-linear confirmation of the supply and demanding between the producer and the customer, the producer being the medium, is confirmed further in the way of linear connection. Obviously, the integration result managed by the way of the interface integration may bring the emerging functions for the interface integration of the enterprises having direct supply and demanding relationship, but for the whole supply chain's integration, the double effect will come into being on the basis of the whole function of the enterprises.

Fig. 2-c indicates that when the information technology is highly advanced, the whole operation of each knotted enterprises in the supply chain is based on the enterprises' management interface through the non-linear confirmation of the respective management interface of the value entities in the enterprises. The entirety and corporation operation of all the knotted enterprises in the supply chain is also based on the formed supply chain management interface through the non-linear confirmation of the respective management interface. With the aid of the supply chain management integration interface, the management in coordination can be realized among the arbitrary enterprises in the supply chain (direct and indirect supplying and demanding relationship), and finally the functions of the supply chain are emerged.

The function emerging of the supply chain integration is mainly demonstrated in two aspects: one is the function emerging of the respond speed and agile degree, because the influence on the Bullwhip Effect is decreased to the lowest essentially through the interface integration so that the response rapid appears the function emerging, which can be demonstrated by $E_{A}+E_{A}+E_{A}=E_{A}$; On the other side, with the aid of the integration interface, the exchange among the arbitrary sections may bring about new functions. For example, a section with new functions will be possibly confirmed through the exchange among R\&D sections, and R\&D sections with the other manufacturing sections and intermediate-testing sections to be in charge of a new product's R\&D and marketing, which can be demonstrated by $E_{A}+E_{B}+E_{C}=E_{D}$, showing that the new functions appear through the integration. Here the function emerging can be understood as the $t$ contents in two aspects, the predetermined function's non-linear enormous emerging and the functions innovation.

Through the analysis on the categories of the supply chain management interface integration, it is known that the second and third management interface integration are build on the highly developed information technology, With the development of IT and Internet, information will be separated with management and becomes the important sources of the enterprise and the independent manufacturing factor. Thus the management orders through the management interface will be affected on the management objects by the means of information; information has become the medium between the management and the management object. Compared to the management interface, information interface still exists. With the strengthening of the information interface function, many functions of the 
management interface are complemented through the information interface. Through the information interface, the management interface acts on the management object, which is the reveal of the mechanism of the enterprises' operation management. Fig. 3 shows that inner process of the management interface acting on the management object.

\section{Analysis on the supply chain integration mode based on the management interface integration}

In the research of the supply chain integration, Stevens and Graham proposed 4 stages [5]. Shihua developed it to be the 5 stages based on Stevens [6]. With the aid of the principle of the management interface integration, the outer integration of the supply chain (Steven's fourth stage and Shihua's fourth and fifth stage) is divided into 3 categories, which is divided under the circumstances of the highly development of the IT. Different categories will have different operation modes.

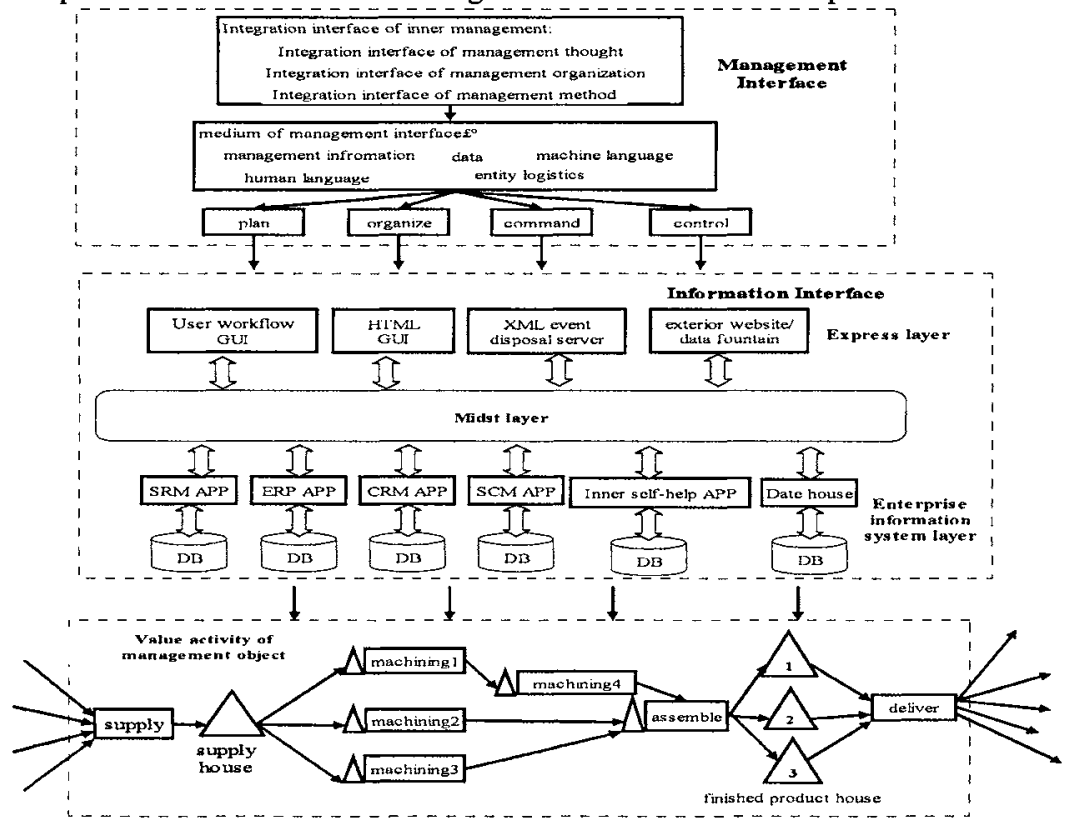

Fig. 3. schematic diagram of the operation of the management interface in the enterprise 


\subsection{Supply Chain Integration Mode of the Linear Confirmation of the Information Interface and Management Interface}

The knotted enterprises of the supply chain all have their own information interfaces and management interfaces, it's highly effectively corporation is done through the management interface in the enterprise. But the value increasing activities of the supply chain is realized through the flow of the materials, semiproduct and product among the knotted points among the enterprises. Through the connection of the information interface among the enterprises, the information exchange is realized; through the connection of the management interface, the control of the supply chain management is realized, the specific supply chain integration mode can be seen in Fig 4. The confirmation between the information interface and management interface in the supply chain is all based on the linear connection, compared to the supply chain structure based on the supply and demanding relationship of the complete competition, the functions to merge the supply chain increase. But this kind of mode exists Bullwhip Effect of the information, thus the integration effect of the supply chain will be affected.

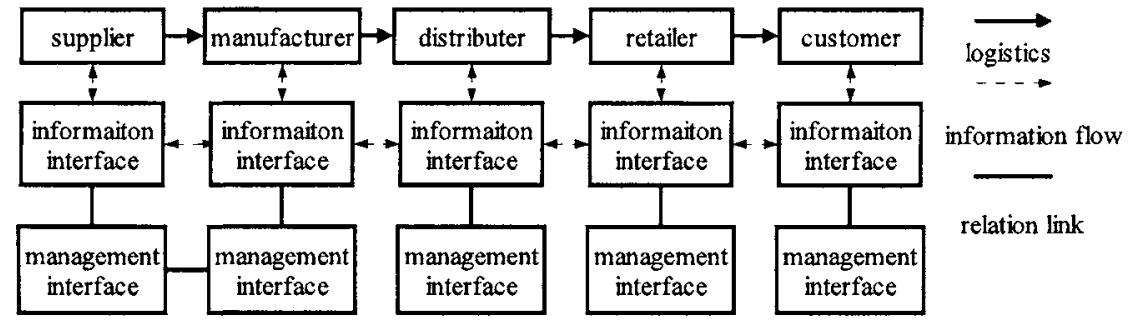

Fig. 4. Supply Chain Integration Mode of the Linear Confirmation of the Information Interface and Management Interface

\subsection{Supply chain Integration Mode of the non-linear Confirmation information interface and the Linear Confirmation of the Management Interface}

In the first supply chain integration mode, a large amount of energy will be consumed to eliminate the Bullwhip Effect when the information is transmitted, and to balance and handle the connection of different information systems, which will cost a lot. With the increase of the knotted points in the supply chain, the cost will increase linearly. Certainly the supply chain benefit will increase linearly with the increase of the management interface intensity.

With the development of the IT, the integration of the enterprise's information interface in the different knotted joints of the supply chain will be realized through the middle layer, so that the enterprises can be connected through the integration's information platform and get the needed information through the share of the information. But the traditional series structure mainly exists in the management interface; the management interface integration between the two supplying and 
demanding enterprises is undertaking independently, each management interface is integrated in the way of linear series connection after the integration of the management integration, See Fig 5. In this supply chain integration mode, the supply chain and policy response is far lower than the information-getting rapid, which shows that the information synchronization can be realized technologically in the knotted enterprises of the supply chain. But the management's failure in synchronization will affect the synchronization of the information, so that synchrologistics and synchro-production is difficult to be realized and the goal of the agility, quickness and flexibility of the supply chain is also hard to be realized.

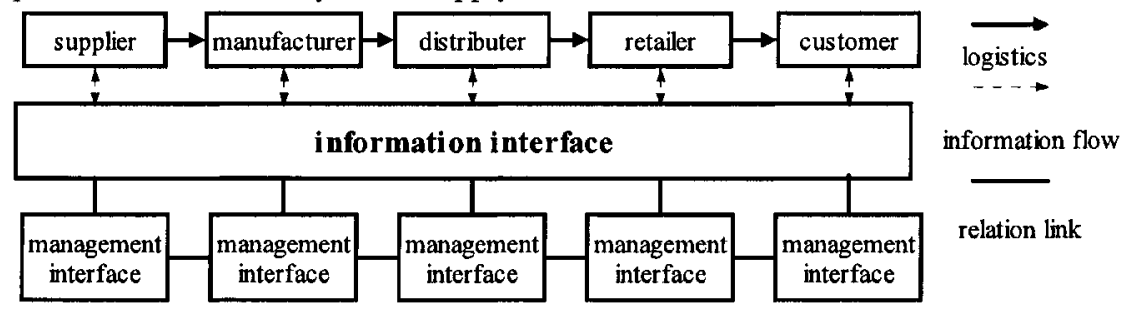

Fig. 5. The Supply Chain Integration Mode of the non-linear Confirmation of the information interface and linear Confirmation of the management interface

\subsection{The Supply Chain Integration Mode of the Non-Linear Confirmation of the Information Interface and Management Interface}

Supported by the IT, many functions of the management can be realized through the information system that provides the guarantee for the integration of the management interface. Through the analysis on the properties of mutual mixing and complementing and under one common goal, the management interface of the knotted enterprises in the supply chain is confirmed effectively, while the logistics and the flow of the information, work, fund and value are handled and bettered, to realize the synchronization of the information and management in the supply chain, so that the synchronic logistics and synchronic flow of information and production will be realized, and finally the function emerging of the integrated supply chain will come into being, see Fig 6 . The benefit the supply chain gets is that Pareto Efficiency in the real meaning.

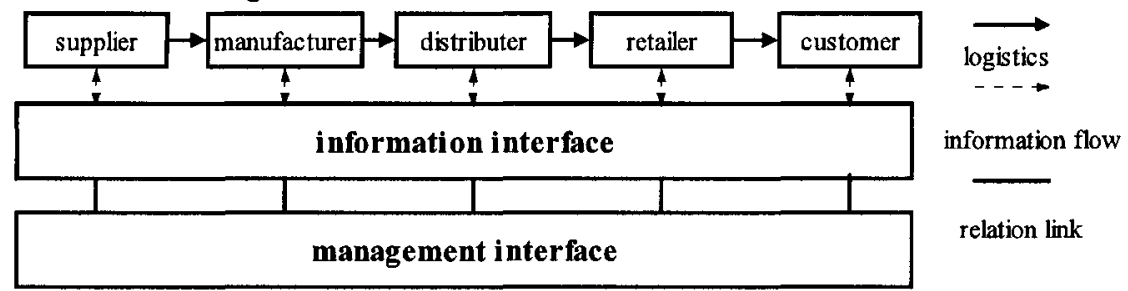

Fig. 6. The Supply Chain Integration Mode of the non-linear confirmation of the management interface and information interface 


\section{Conclusions}

Through the analysis on the management philosophy of the supply chain management and the supply chain integration, the conception of the management interface is proposed, three categories of the supply chain interface integration are given, and the difference of the supply chain function, resulted by the management integration through the three management integration methods, is explained. Finally through the mechanic analysis on the management interface integration principle and on the basis of Steven's etc supply chain integration, the three integration modes of the supply chain based on the management interface integration are raised.

\section{Acknowledgements}

This paper is supported by the National Natural Science Foundation of China (70332001).

\section{References}

1. J.T. Mentzer and W. DeWitt, Defining Supply Chain Management, Journal of Business Logistics 22(2), 1-26 (2002).

2. L.M. Ellram and M.C. Cooper, Supply Chain Management, Partnerships, and the ShipperThird-Party Relationship, The International Journal of Logistics Management 2, 1-10 (1990).

3. G. Tyndall, C. Gopal, W. Partsch, and John Kamauff, Supercharging Supply Chains: New Ways to Increase Value Through Global Operational Excellence (New York, NY: John Wiley \& Sons).

4. J.B. Houlihan, International Supply Chains: A New Approach, Management Decision 3, 1319 (1998).

5. G.C. Stevens, Integrating the Supply Chains, International Journal of Physical Distribution and Materials Management 8, 3-8 (1989).

6. M. Shihua, Supply Chain Management (Beijing, Machinery Industrial Press, April 2004).

7. X.M. Song and B. Dyer, Innovation Strategy and the R\&D - Marketing Interface in Japanese Firms: A Contingency Perspective, IEEE Transactions on Engineering Management, 42(4), 361-381 (1995).

8. X. Xiaoxuan, The Business Process Integration Methods in the Enterprises' Applied Integration. (in Chinese)

9. H. Feng, F. Yanfei, and L. Biqiang. The Basic Category of the Management Integration Theories, The Journal of System Dialectic, 4, 44-48 (2000). (in Chinese)

10. W. Tao, H. Feng, and L. Biqiang, Interface and Management Interface Analysis, Chinese Management Science 1, 6-10 92003).

11. S. Houcai and T. Qing, Supply Chain Management Theories and Methodology, Chinese Management Science 1, 1-9 (2000).

12. W. Chengen, Logistics and Information Stream Management in Supply Chain, Chinese Management Science 4, 16-23 (2000). 